\title{
Veterinary sanitary assessment of chicken meat using squalene
}

\author{
Igor Kirillov*, Rezilya Asrutdinova, Leysan Yakupova, Rustem Gilmutdinov, and G.A. Fayzrakhmanova \\ Kazan State Academy of Veterinary Medicine named after N.E. Bauman, Kazan, 420029, Russia
}

\begin{abstract}
One of the most promising sectors of agriculture is poultry farming. There are many unresolved problems, such as deaths of young birds during the first weeks of life due to the unstable immune system that develops by the end of the third week. The development and use of new immunomodulators (adjuvants) together with vaccines is a promising direction for enhancing and maintaining the natural resistance of birds and increasing their productive and economic indicators. The authors used a vaccine produced by VNIVIP a branch of the Federal Scientific Center VNITIP RAS (St. Petersburg, Lomonosov). 45 chickens were divided into 3 groups. The control over the experimental birds was carried out until they are sixteen weeks old. An inactivated, emulsified vaccine with squalene in a dose of $0.5 \mathrm{~cm}^{3}$ was administered. Squalene is a natural unsaturated hydrocarbon which belongs to an extensive group of isoprenoids, which include $\beta$ carotene, ubiquinone, and tocopherol. In its pure form, squalene is colorless oil, odorless and tasteless, characterized by physical and chemical stability and a high boiling point. 15 birds were vaccinated against the Newcastle disease without an adjuvant, and 15 remained intact. According to the results of organoleptic, physico-chemical and microscopic studies of chicken meat, it was found that the carcasses of experimental birds met the veterinary and sanitary requirements for high quality meat obtained from healthy birds and can be sold.
\end{abstract}

\section{Introduction}

The fastest growing sector of agriculture is the poultry industry which provides the population with highly nutritious and dietary foods $[1,2]$. Poultry meat, unlike meat of other farm animals has a delicate texture, pleasant aroma, juiciness, good taste, contains essential amino acids, trace elements (cobalt, iron, etc.), vitamins B. It is a dietary product [3-5].

The poultry industry uses immunomotors in order to increase the viability and resistance of birds to diseases and stresses. Immunomodulators are drugs that restore functions of the body's immune system [6-11].

Unfortunately, many of the immunomodulators that are currently used cannot fully increase the resistance of birds to diseases. Therefore, the development and search for new drugs that would have a wide spectrum of action is a very urgent task [12-16].

The need for the use of adjuvants that have an immunostimulating effect is due to the fact that many vaccines have weak immunogenicity. Adjuvants are substances that increase the immune potential of vaccines. Thanks to their use, the immunogenicity of individual vaccines is enhanced by tens and even hundreds of times. Continuous work aimed at the search, development and introduction of new highly effective adjuvants has reduced the number of booster vaccines and the antigenic load on the body, significantly reducing the cost and simplifying the vaccination process. Despite the huge selection of adjuvants in experimental immunology, their use is limited [18-24].
Squalene is a natural unsaturated hydrocarbon which belongs to a group of isoprenoids, which include $\beta$ carotene, ubiquinone, tocopherol. It is colorless oil, odorless and tasteless, characterized by physical and chemical stability and a high boiling point. It is synthesized in the liver and circulates in the blood. Previously, it was obtained mainly from shark liver. Before using squalene for producing vaccines, it was preliminarily purified. Later, the traditional method was replaced by the production of olive oil, wheat germ oil and rice bran oil. Squalene is not an adjuvant, but joint emulsions enhance the immune response [25-28].

The purpose of the research is to study the effect of squalene used together with the vaccine against Newcastle disease on the quality of chicken meat.

\section{Materials and methods}

The studies were conducted in the Sabin district of the Republic of Tatarstan. 45 chickens were divided into 3 groups. The studies were conducted during 16 weeks. An inactivated, emulsified Newcastle disease vaccine was administered to the bird of the first group along with squalene in a dose of $0.5 \mathrm{~cm}^{3}$. The control group was immunized with the Newcastle disease vaccine without an adjuvant, and 15 chickens remained intact. All the studies were conducted without changing the technological process of production under the same conditions. The zoohygienic conditions of keeping and

Corresponding author: igor.kirillo2017@yandex.ru 
watering the birds were analyzed by studying the main microclimate parameters.

When studying the keeping conditions, the constructive, space-planning solution of buildings, safety and growth of young birds were taken into account. Zoohygienic studies were carried out in a poultry house. The parameters of the air were controlled by generally accepted methods.

After the end of the experiment, all experimental chickens were slaughtered, followed by veterinary and sanitary examination of slaughter products after 24 hours of storage at a temperature of $+2,+4{ }^{\circ} \mathrm{C}$.

When conducting a post-slaughter veterinary-sanitary inspection of carcasses, we were guided by the "Rules of veterinary inspection of slaughtered animals and veterinary-sanitary examination of meat and meat products". Sampling for research was carried out in accordance with GOST 31467-2012 "Poultry meat, offal and semi-finished products from poultry meat. Sampling methods and their preparation for testing".

According to GOST R 51944-2002 and GOST 31962-2013, an organoleptic study of carcasses was carried out, the appearance of the surface of the carcasses, serous membrane of the abdominal cavity, as well as subcutaneous and internal adipose tissues were studied. In addition, we evaluated the muscles in the section, their consistency, smell, transparency and aroma of the broth. In addition, we evaluated the quality of carcass processing and fatness of carcasses.

The physico-chemical analysis of meat was carried out according to GOST 7702.2-74 "Poultry meat. Methods of chemical and microscopic analysis of meat freshness". The following indicators were studied:

- $\mathrm{pH}$

- response to peroxidase enzyme activity

- response to ammonia and ammonium salts with Nessler's reagent;

- microscopic analysis

The laboratory studies, including physico-chemical analysis and microscopy, were carried out in accordance with GOST 31470-2012 and GOST 31931-2012. The pH of the meat extract was determined using the potentiometric method with a $\mathrm{pH}-150 \mathrm{MI}$ device. The presence of ammonia and ammonium salts was determined with the Nessler reagent, the activity of the peroxidase enzyme was determined by the benzidine test.

The microscopic analysis was based on determining the number of bacteria and the degree of decomposition of muscle tissue by microscopy of smears. Meat was considered:

- fresh, if microflora was not found in the smearprints or single (up to 10 cells) cocci and rod-shaped bacteria were visible and there were no traces of muscle tissue decay; preparation - the imprint is colored poorly;

- of doubtful freshness - no more than 30 cocci and rods, traces of muscle tissue decay: the nuclei of muscle fibers were decayed, the striated fiber is hardly distinguishable;

- stale - over 30 cocci and rods, significant decay of tissues: the complete disappearance of nuclei and the complete disappearance of striated muscle fibers. The imprint preparation is highly colored.

The concentration of hydrogen ions $(\mathrm{pH})$ was determined by the potentiometric method. In maturing, lactic acid accumulates and the concentration of hydrogen ions increases. Lactic acid is present in an insignificant amount, therefore, the reaction of the muscle changes slightly.

Peroxidase enzyme activity. The peroxidase enzyme decomposes hydrogen peroxide to form oxygen, which oxidizes benzidine. As a result of the oxidation of benzidine, paraquinondiamide is formed, which gives a compound colored in bluish-green turning into brown. During the reaction, peroxidase activity is important. In the meat of healthy birds, it is very active, in the meat of sick burds, its activity is weak.

If the meat was obtained from a healthy bird, the is blue-green turning into brown-brown within 1-2 minutes. If the hood is blue-green or brown-brown, the meat was obtained from a sick bird.

The method for determining ammonia and ammonium salts is based on the ability of ammonia and ammonium salts to form mercurrammonium iodide, a yellow-brown substance with the Nessler reagent. The meat was considered fresh if the hood was greenishyellow while maintaining transparency; dubious freshness - intense yellow color sometimes with an orange tint; significant turbidity with the deposition of a thin layer of sediment after settling for 10-20 minutes; stale yellowish-orange staining; rapid formation of large flakes was observed.

The fat content in muscle tissues was determined according to GOST 23042-86 "Meat and meat products. Methods for determining fat", moisture content according to GOST 9793-74 "Meat products. Methods for determining moisture", protein - according to GOST 25011-81"Meat and meat products. Methods for determining protein".

The research results were processed in Microsoft Excel 2010; the arithmetic mean (M), the average statistical errors (m) and the reliability criterion (p) were calculated; the numerical data were evaluated using the Student's confidence level.

\section{Results}

Premises for breeding chickens are typical. The buildings are rectangular, windowless, consisting of poultry halls and utility rooms. The houses are equipped with an internal water supply system; the heat supply is provided by electric heaters and brooders.

The zone of the production sector is landscaped by planting perennial grasses, trees are used for wind erosion. All roads and entrances are primed.

Due to the combined ventilation system, sanitary and hygienic conditions for keeping chickens are ensured, the technological processes are normalized and an appropriate microclimate is created.

Fluctuations in temperature, air humidity, and the content of harmful gases were within the limits. There are incandescent lamps. A bird behaves calmer if it is 
light. This is achieved by using a correct color and eliminating unwanted colors.

Density per $1 \mathrm{~m}^{2}$ was 16 birds. At an older age, density should not exceed $8-12$ birds $/ \mathrm{m}^{2}$. The health and productivity depend on the density: the higher it is, the more often diseases develop, the viability and safety are reduced. Excessive density creates a negative effect on the body and reduces the profitability of production.

According to the most important indicators of the microclimate, the air environment corresponds to the hygiene standard and is favorable for the development of birds.

According to many organoleptic and physicochemical indicators, water quality meets the hygiene requirements.

Much attention is paid to the control over harmful and prohibited substances in agricultural products. The veterinary and sanitary assessment of poultry products using various chemical and other substances plays a special role.

The organoleptic characteristics of meat depend on multiple factors, biochemical processes in meat after slaughte, which determine the degree of maturation.

During the post-slaughter examination, it was found that the carcasses and internal organs of birds did not have significant differences. The carcasses were well bled, had no foreign inclusions and blood clots. When determining fatness and processing quality, the carcasses of all experimental groups were assigned to the first grade - the muscles were well developed, the breast was round, the keel of the sternum was not prominent, deposits of subcutaneous fat were found in the lower back and abdomen, the skin was clean, without tears, scratches, spots, abrasions and bruises, the skeletal system had no deformations or fractures.

The examination of the internal organs showed that they had a typical color and shape, proportional sizes and did not differ. Pathological changes in the internal organs were not found.

The results of the organoleptic study showed that the carcasses of chickens had identical characteristics, namely, the surface color of all carcasses was whitishyellow with a pink tint, the subcutaneous and internal adipose tissue was pale yellow; on the surface of all carcasses, there was a dry crust of drying. The smell of meat was specific, characteristic of fresh poultry. The serous membrane of the abdominal cavity was moist, shiny, without mucus and mold. The muscle tissue was dense, the section of the pectoral muscles was pale pink, the pelvic muscles were dark pink, slightly moist. On the surface and at the depth of the section, the smell was specific, characteristic of fresh poultry.

When evaluating the broth for transparency and aroma, it was revealed that the broth prepared from poultry of all groups was transparent and fragrant, fat was in the form of large drops. The quality of the broth from meat of the experimental groups corresponded to the broth of the control group.

Of the physico-chemical indicators characterizing the quality of the meat, the $\mathrm{pH}$ value is important, since the depth of autolysis and the ability of meat to be stored depend on it. The $\mathrm{pH}$ of muscle tissue is dependent on the amount of lactic acid formed from glycogen during the anaerobic glycolysis. The content of glycogen and lactic acid is reduced due to fatigue, starvation, stress and pathological processes at the time of slaughter. Table 1 shows that the $\mathrm{pH}$ value in the white muscles of birds of all groups is 5.8-6.02; in red muscles $6.02-6.22$, with no significant difference in the groups. The process of meat maturation occurred synchronously in all experimental groups and more intensively in the pectoral muscles.

Table 1. Results of laboratory studies of muscle and adipose tissues of experimental birds

\begin{tabular}{|c|c|c|c|}
\hline \multirow{2}{*}{ Parameter } & \multicolumn{3}{|c|}{ Group } \\
\cline { 2 - 4 } & experimental & control & intact \\
\hline \multicolumn{3}{|c|}{ Red muscles (femoral) } \\
\hline $\mathrm{pH}$ & $6.09 \pm 0.08$ & $6.02 \pm 0.09$ & $6.22 \pm 0.06$ \\
\hline Peroxidase response & Positive & Positive & Positive \\
\hline $\begin{array}{c}\text { Ammonia and } \\
\text { ammonium salts }\end{array}$ & Negative & Negative & Negative \\
\hline The number of bacteria & $2.8 \pm 0.42$ & $3.2 \pm 0.65$ & $2.6 \pm 0.45$ \\
\hline \multicolumn{4}{|c|}{ White muscles (pectoral) } \\
\hline pH & $5.80 \pm 0.08$ & $5.96 \pm 0.06$ & $6.02 \pm 0.07$ \\
\hline Peroxidase response & Positive & Positive & Positive \\
\hline $\begin{array}{c}\text { Ammonia and } \\
\text { ammonium salts }\end{array}$ & Negative & Negative & Negative \\
\hline The number of bacteria & $2.0 \pm 0.35$ & $2.8 \pm 0.42$ & $2.8 \pm 0.42$ \\
\hline \multicolumn{4}{|c|}{ Fat tissue } \\
\hline Acid number, mg KOH/g & $0.28 \pm 0.08$ & $0.30 \pm 0.10$ & $0.32 \pm 0.07$ \\
\hline
\end{tabular}

The reaction of aqueous extracts from white and red meat to ammonia and ammonium salts with Nessler's reagent was negative in all groups, and the peroxidase muscle tissue enzyme was active in red and white muscles. The activity of the peroxidase enzyme indicates that during the slaughter, the bird was healthy and not subjected to stress.

Table 2. Tasting evaluation of meat and broth, score

\begin{tabular}{|c|c|c|c|c|c|c|c|c|c|}
\hline \multirow[b]{2}{*}{ Parameter } & \multicolumn{3}{|c|}{ Boiled meat } & \multicolumn{3}{|c|}{ Fried meat } & \multicolumn{3}{|c|}{ Broth } \\
\hline & experimental & control & intact & experimental & control & intact & experimental & control & intact \\
\hline Aroma (smell) & 4.96 & 4.94 & 4.95 & 4.95 & 4.94 & 4.93 & 4.96 & 4.94 & 4.90 \\
\hline Taste & 4.97 & 4.92 & 4.94 & 4.94 & 4.93 & 4.94 & 4.95 & 4.94 & 4.93 \\
\hline Tenderness (rigidity) & 4.95 & 4.95 & 4.92 & 4.96 & 4.93 & 4.92 & - & - & - \\
\hline succulence & 4.96 & 4.93 & 4.96 & 4.96 & 4.92 & 4.92 & - & - & - \\
\hline Transparency & - & - & - & - & - & - & 4.95 & 4.93 & 4.92 \\
\hline richness & - & - & - & - & - & - & 4.97 & 4.95 & 4.90 \\
\hline Total score & 19.83 & 19.74 & 19.77 & 19.81 & 19.72 & 19.71 & 19.83 & 19.76 & 19.65 \\
\hline Average score & 4.95 & 4.93 & 4.94 & 4.95 & 4.93 & 4.92 & 4.95 & 4.94 & 4.91 \\
\hline
\end{tabular}


The microscopy of tissue smears from the deep layers of the muscle tissue of the pectoral and femoral muscles showed that single microbial cells were found which meets the requirements of current regulatory and technical documents for benign and safe poultry meat.

Samples to determine the products of primary protein breakdown showed an identical negative result. The acid number of fat in the control, experimental and intact samples was $0.30 \pm 0.10,0.28 \pm 0.08,0.32 \pm 0.07 \mathrm{mg}$ $\mathrm{KOH} / \mathrm{g}$, respectively.

Taste qualities of meat of experimental chickens were evaluated by the tasting commission according to a five-point scale using the VNITIP method [17].

Analyzing the data in Table 2, we can conclude that vaccination of chickens in combination with squalene did not adversely affect the taste of meat; by the organoleptic characteristics, it met the requirements of the standard; by the veterinary and sanitary requirements it is of high quality.

To determine the qualitative composition of the meat of experimental chickens, a chemical analysis of the muscle tissue of the experimental chickens was performed (Table 3).

Table 3. The chemical composition of meat of chickens, $\%$

\begin{tabular}{|c|c|c|c|}
\hline \multirow{2}{*}{ Parameter } & \multicolumn{3}{|c|}{ Group } \\
\cline { 2 - 4 } & experimental & control & intact \\
\hline Moisture & $72.32 \pm 0.29$ & $73.27 \pm 0.37$ & $73.04 \pm 0.22$ \\
\hline Dry matter & $27.68 \pm 0.34$ & $26.73 \pm 0.48$ & $26.96 \pm 0.30$ \\
\hline Protein & $22.31 \pm 0.15^{* * *}$ & $21.47 \pm 0.13$ & $21.82 \pm 0.17$ \\
\hline Ash & $1.15 \pm 0.10$ & $1.17 \pm 0.11$ & $1.22 \pm 0.11$ \\
\hline Fat & $2.28 \pm 0.09$ & $2.16 \pm 0.08$ & $2.24 \pm 0.07$ \\
\hline *** $-\mathrm{p} \leq 0.01$
\end{tabular}

An analysis of the data in Table 3 showed that the chemical composition of meat of the experimental and control chickens was slightly different, but within the normal range and corresponded to GOST R 52702-2006.

\section{Conclusion}

Thus, the results of organoleptic, physico-chemical and microscopic studies of chicken meat showed that the carcasses of experimental birds meet the veterinary and sanitary requirements for high quality meat obtained from healthy birds and can be sold.

\section{References}

1. S. Zibrov, A. Ratoshny, Effect. animal husbandry, 5, 58 (2011)

2. V. Kuritsyna, Veterinary and sanitary assessment of broiler chicken meat when using sapropel extract in the diet (St. Petersburg, 2008)

3. N. Arestova, Quail productivity based on culling age (Moscow, 2007)

4. T. Afanasyeva, A. Volkov, Sci. notes of Kazan SAVM, 208, 3-6 (2011)

5. A. Nadtochy, Bull. of NSAU, 4(45), 96-102 (2017)
6. R. Asrutdinova, M. Sagitova, A. Kamaliev, Sci. notes of Kazan SAVM, 217, 12-16 (2014)

7. S. Garipov, R. Asrutdinova, L. Yakupova, Sci. notes of Kazan SAVM, 231, 15-18 (2017)

8. A. Ratoshny, S. Zibrov, Effect. animal husbandry, 3, 28-30 (2012)

9. A. Subbotin, A. Yatusevich, Biological and environmental fundamentals of the prevention of parasitosis of wild ungulate and predatory mammals in Belarus (Vitebsk, 2009)

10. A.M. Subbotin, Parasitic systems of wild ungulates and carnivores and the basics of the prevention of parasitoses in Belarus (Vitebsk, 2011)

11. L. Topuria, G. Topuria, Veter. of the Kuban region, 4, 3-4 (2010)

12. L. Topuria, G. Topuria, E. Grigoryeva, Veter. Med. of the Kuban region, 1, 12-13 (2012)

13. A.F. Khabirov, F.S. Khaziakhmetov, R. Avzalov, Bull. of KrasSAU, 8, 170-174 (2016)

14. A. Imani Fooladi, M. Sattari, M. Reza Nourani, J. BUON, 15(2), 340-347 (2010)

15. F. Petryankin, O. Petrova, Veter. Consult., 20, 8-20 (2007)

16. V. Zverev, M. Boitchenko, GEOTAR-Media, 1 (2010)

17. V. Lukashenko, M. Lysenko, T. Stollyar et al., Methodological recommendations for anatomical cutting of carcasses and organoleptic quality assessment of meat and eggs of poultry and egg morphology (VNITIP, Sergiev Posad, 2004)

18. D. Webster, P. Sundaram, M. Byrne, Europ. J. of Pharmaceut. and Biopharmaceut., 84(1), 1-20 (2013)

19. V. Behalo, E. Sysolyatina, E. Nagurskaya, Herald of the Russ. Acad. of Sci., 4, 75-80 (2010)

20. O. Steinbach, Therapeutic Delivery, 4(5), 531-535 (2013)

21. P. Vladimir, Therapeutic Delivery, 4(5), 537-538 (2013)

22. R. Niven, Therapeutic Delivery, 4(5), 519-522 (2013)

23. L. Vasconcelos, K. Pärn, Ü. Langel, Therapeutic Delivery, 4(5), 573-591 (2013)

24. C. Foged, Therapeutic Delivery, 2(8), 1057-1077 (2011)

25. E. Muzalevskaya, L. Miroshnichenko, V. Nikolaevsky, I. Ushakov, Yu. Chernov, V. Alabovsky, G. Batishcheva, A. Buzlama, Experim. and Clin. Pharmacol., 78(6), 30-36 (2015)

26. S. Sayers, G. Ulysse, Z. Xiang et al., J. of Biomed. and Biotechnol., 10 (2012)

27. G. Matyas, M. Rao, P. Pittman et al., JIM, 47-67 (2004)

28. V. Pillay, P. Kumar, Lisa C du Toit et al., Therapeutic Delivery, 4(3), 285-287 (2013) 